\title{
RELAÇÕES DE CONFIANÇA E SATISFAÇÃO COM AS CONDIÇÕES SOCIAIS EM UMA MICROBACIA EM MINAS GERAIS
}

\section{RESUMO}

\author{
Myriam Angélica Dornelas ${ }^{1}$ \\ Anderson Alves Santos ${ }^{2}$ \\ Maurício Lourenço Jorge ${ }^{3}$
}

O objetivo deste trabalho é apresentar a percepção sobre as relações de confiança com relação a órgãos de apoio ao produtor rural e satisfação com as condições sociais dos agricultores (pequeno, médio e grande porte) da microbacia dos Córregos São Pedro e Araras no município de Bambuí - MG. Para tanto foi realizada uma pesquisa qualitativa, baseada em um estudo descritivo. A coleta de dados foi feita por meio da aplicação de questionário semiestruturado a 70 produtores inseridos na microbacia. Obteve-se que as instituições que inspiraram maior confiança, demonstrando laços mais fortes pelos produtores foram, na ordem de importância, a família, os vizinhos, EMATER, universidades, igreja, IBAMA, IEF e ministério público. Com relação à satisfação com as condições sociais, os principais fatores limitantes foram ligados principalmente às condições das estradas e falta de apoio aos pequenos produtores (assistência técnica, informação sobre políticas públicas). Concluiu-se que na microbacia estudada há a presença de boas relações de confiança entre as famílias e os vizinhos, demonstrando um capital social comunitário forte.

Palavras-chave: Microbacia. Capital social. Relações de confiança. Satisfação.

\section{INTRODUÇÃO}

Um dos maiores desafios da sociedade moderna é garantir a utilização dos recursos naturais associada ao crescimento econômico de forma sustentável. Este crescimento sustentável é esperado tanto no meio urbano quanto no âmbito rural. Esse desafio é crescente

\section{Como citar este artigo:}

DORNELAS, M. A.; SANTOS, A. A.; JORGE, M. L. Relações de confiança e satisfação com as condições sociais em uma microbacia em Minas Gerais. ForScience: revista científica do IFMG, v. 5, n. 2, e00306, out. 2017. Edição especial.

\footnotetext{
${ }^{1}$ Doutorado em Ciências Florestais (DCF/UFLA), mestrado em Administração pela Universidade Federal de Lavras (PPGA/UFLA) e professora efetiva do IFMG - Campus Bambuí. Currículo Lattes: http://attes.cnpq.br/9746082351894970. E-mail: myriam.dornelas@ifmg.edu.br.

${ }^{2}$ Pós-doutorado em Engenharia Florestal (DCF/UFLA), doutorado em Ciências Florestais (DCF/UFLA), mestrado em Administração (PPGA/UFLA), especialista em Marketing (FACED), bacharel em Turismo (FATUR/MG) e professor efetivo do IFMG - Campus Formiga. Currículo Lattes: http://lattes.cnpq.br/7747265989770754.E-mail: alves.santos@ifmg.edu.br.

${ }^{3}$ MBA em Gestão Estratégica de Negócios (VERIS/METROCAMP/SP), graduação em Engenharia Mecânica (UNICAMP/SP) professor efetivo do IFMG - Campus Avançado de Arcos. Currículo Lattes: http://lattes.cnpq.br/4027734972678176. E-mail: mauricio.jorge@ifmg.edu.br.
} 
DORNELAS, M. A.; SANTOS, A. A.; JORGE, M. L. Relações de confiança e satisfação com as condições sociais em uma microbacia em Minas Gerais

em todo o mundo à medida que se intensificam os impactos ambientais, a pobreza, a desigualdade social e a necessidade de segurança alimentar.

Os Governos, a sociedade civil, organizações internacionais, setor privado e outros atores devem trabalhar juntos para enfrentar esses desafios e desenvolver estratégias apropriadas de combate a esses problemas. Assim, é importante que se criem condições para compatibilizar o desenvolvimento socioeconômico com vistas a uma exploração ambientalmente sustentável.

Especificamente no meio rural, boa parte dos impactos ambientais é resultado de técnicas de manejo inadequadas, desmatamento, uso indiscriminado de agrotóxicos, destinação incorreta de resíduos, entre outros. Economicamente, destaca-se como problema a falta de planejamento e controle econômico da produção e comercialização. Essas práticas, comuns no modelo agrícola convencional, que adota práticas intensivas, produção em escala industrial e alta demanda de agroquímicos, geram uma série de impactos negativos ao meio ambiente e diretamente ao produtor rural.

Quanto aos entraves no aspecto social, o produtor rural enfrenta questões que vão desde o acesso ao sistema de saúde, aos meios de comunicação e mídia, à capacitação profissional, educação de seus filhos, boas condições de estradas e transporte. Além disso, os produtores rurais podem ter reduzidas suas atividades de lazer e culturais, fator importantíssimo para a qualidade de vida.

Mais importante do que a necessidade de investir recursos financeiros - muitas vezes acima da capacidade de pagamento gerada pela atividade desenvolvida - na implementação de práticas voltadas para a recuperação/conservação dos recursos naturais, é fundamental que haja, por parte dos produtores, uma percepção para a detecção dos problemas, conhecimento dos fatores que originaram tais problemas e busca de alternativas que recuperem a potencialidade produtiva da propriedade rural. É necessária uma nova compreensão sobre as causas dos problemas e uma reformulação de conceitos ambientais, econômicos e sociais para se chegar a uma solução adequada.

A percepção sobre as formas que devem ser utilizadas e, posteriormente, o manejo da(s) área(s), deve partir de uma visão do conjunto, de uma abordagem sistêmica, elaborada, pelo menos, no nível de microbacias. Atitudes isoladas, em uma ou outra propriedade, são insuficientes para resolução do problema como um todo. O gerenciamento de bacia hidrográfica é o instrumento orientador das ações do poder público e da sociedade, em longo 
DORNELAS, M. A.; SANTOS, A. A.; JORGE, M. L. Relações de confiança e satisfação com as condições sociais em uma microbacia em Minas Gerais

prazo, no controle do uso dos recursos ambientais - naturais, econômicos e socioculturais pelo homem, com vistas ao desenvolvimento sustentável.

As estratégias de uso sustentável dos recursos rurais variam conforme a comunidade considerada e sua localização. As demandas sociais são múltiplas e há sempre dificuldades para compatibilizá-las. A solução não é simples, pois há diferentes perspectivas e necessidades dos diferentes atores sociais da comunidade. Este é um processo no qual há constantes conflitos de interesses, uma vez que os limites socioculturais são visualizados de forma diversa por diferentes usuários de uma mesma área, como se pode perceber na decisão sobre recuperação de pastagens versus extração de madeira versus lazer. É importante que se identifiquem estas demandas e capacidades para que se possa ajustá-las, permitindo a construção de um processo de planejamento e gestão, que tenha como princípios norteadores a participação comunitária e o processo de construção social coletiva "de baixo para cima".

A agricultura, nesse sentido, precisa ser entendida como atividade econômica e sociocultural - uma prática social - realizada por sujeitos que se caracterizam por uma forma particular de relacionamento com o meio ambiente. Esta faceta da dimensão cultural não pode e não deve obscurecer a necessidade de um processo de problematização sobre os elementos formadores da cultura de um determinado grupo social. Nesse contexto, o desenvolvimento rural sustentável deve ser concebido a partir das concepções culturais e políticas próprias dos grupos sociais, considerando suas relações de diálogo e de integração com a sociedade maior, por meio de representação em espaços comunitários ou em conselhos políticos e profissionais, numa lógica que considera aquelas dimensões de primeiro nível como integradoras das formas de exploração e manejo sustentável dos agroecossistemas.

O presente trabalho apresenta as relações de confiança e satisfação com as condições sociais, elencadas pelos produtores rurais da micro-bacia hidrográfica dos Córregos São Pedro e Araras no município de Bambuí - MG.

\section{ARCABOUÇO TEÓRICO}

\subsection{Desenvolvimento rural sustentável}

Desenvolvimento rural é um conceito sobre o qual se está refletindo no Brasil, que é hoje um país industrializado, mas não desenvolvido, embora nas duas últimas décadas venha 
DORNELAS, M. A.; SANTOS, A. A.; JORGE, M. L. Relações de confiança e satisfação com as condições sociais em uma microbacia em Minas Gerais

apresentando alguns indicadores de desenvolvimento. Este conceito pode ser definido como a melhoria das condições de vida das pessoas residentes nas áreas e regiões rurais, através de processos sociais que respeitem e articulem os seguintes princípios: eficiência econômica, igualdade social e territorial, qualidade patrimonial e ambiental, sustentabilidade, participação democrática e responsabilidade cívica (VACCARI, 2006).

A agricultura sustentável é o manejo e utilização dos ecossistemas agrícolas de forma a manter sua diversidade biológica, produtividade, capacidade de regeneração, vitalidade e habilidade de funcionar de maneira que possa satisfazer - hoje e no futuro - significativas funções ecológicas, econômicas e sociais em nível local, nacional e global, e que não ameace outros ecossistemas (LEWANDOWSKI; HARDTLEIN; KALTSCHMITT, 1999).

Com esta perspectiva, dirime-se a necessidade de atribuir valor diferenciado às alternativas de ocupação do espaço rural, favorecendo a consideração da qualidade e do estado de conservação deste espaço. Aliado ao estado de conservação ambiental da paisagem rural deve-se ainda enfatizar a recuperação das áreas de proteção permanente para atendimento da legislação de proteção ambiental, ou em outras palavras, reverter o presente estado de deterioração da paisagem rural, que se observa na grande maioria das regiões do país (BOWERS; HOPKINSON, 1994). Esta definição de agricultura sustentável imprime ação ao conceito, então identificando-a como tecnologicamente intensiva, ainda que conservadora de recursos (NEHER, 1992).

Segundo Oliveira (2002) e Sachs (1990), destacam a importância de um planejamento agrícola que desenvolva sistemas alternativos de forma a identificar os problemas existentes nas regiões com suas respectivas culturas, expondo a necessidade de mudanças culturais e de comportamento. De acordo com a publicação do Fórum Oeste de Entidades para o Desenvolvimento (2003) os objetivos da agricultura sustentável são: manutenção para longo prazo dos recursos naturais e da produtividade agrícola; o mínimo de impactos adversos ao meio ambiente; retorno adequado aos produtores rurais; otimização da produção das culturas com o mínimo de insumos químicos; satisfação das necessidades humanas em termos de alimentos e de renda e; atendimento das necessidades sociais das famílias e das comunidades rurais.

Conforme o art. 186 da Constituição Federal de 1988, a função social da propriedade rural ocorre quando são cumpridos os requisitos de aproveitamento racional e adequado da terra, utilizando adequadamente os recursos naturais disponíveis e preservando o meio 
DORNELAS, M. A.; SANTOS, A. A.; JORGE, M. L. Relações de confiança e satisfação com as condições sociais em uma microbacia em Minas Gerais

ambiente, observando as disposições que regulam as relações de trabalho em favor do bemestar dos proprietários e dos trabalhadores (BRASIL, 1988). A noção de território favorece os estudos das regiões rurais nas seguintes dimensões: o abandono de uma visão exclusivamente rural, a diferenciação entre o crescimento e o desenvolvimento econômico, a possibilidade de um estudo empírico dos atores e suas organizações e o estabelecimento de uma relação entre os sistemas sociais e ecológicos, com vistas ao desenvolvimento sustentável (ABRAMOVAY, 2006).

No capítulo 14 da Agenda 21 encontram-se recomendações referentes à promoção do desenvolvimento rural e agrícola sustentável. O principal objetivo do desenvolvimento rural e agrícola sustentável é aumentar a produção de alimentos de forma sustentável e incrementar a segurança alimentar. Isso envolverá iniciativas na área da educação, o uso de incentivos econômicos e o desenvolvimento de tecnologias novas e apropriadas, dessa forma assegurando uma oferta estável de alimentos nutricionalmente adequados, o acesso a essas ofertas por parte dos grupos vulneráveis, paralelamente à produção para os mercados; emprego e geração de renda para reduzir a pobreza; e o manejo dos recursos naturais juntamente com a proteção do meio ambiente (CONFERÊNCIA DAS NAÇÕES UNIDAS PARA O MEIO AMBIENTE E O DESENVOLVIMENTO, 1992).

Para que isso aconteça, a comunidade precisa conhecer efetivamente os seus próprios assuntos, ter acesso a recursos, participar do controle desses recursos, participar de decisões e ter acesso a treinamentos, educação, posse da terra e outros direitos de propriedade. É necessário, também, que a comunidade seja capaz de suprir suas necessidades de maneira sustentável, conservando o meio ambiente.

\subsection{Aspectos sociais na atividade rural}

A dimensão social não se refere apenas à distribuição espacial, de gênero e etária da população, mas remete, de maneira especial, ao conjunto de relações sociais e econômicas que se estabelecem em qualquer sociedade e cuja fundamentação é tão variada como a religião, a ética e a própria cultura. De fato, são precisamente essas relações que fundamentam, em boa medida, o grau de acesso às diferentes formas do processo político regional e local (SEPÚLVEDA, 2005). 
DORNELAS, M. A.; SANTOS, A. A.; JORGE, M. L. Relações de confiança e satisfação com as condições sociais em uma microbacia em Minas Gerais

De acordo com Sepúlveda (2005), espera-se que na gestão dos aspectos sociais perceba-se a agregação de atores do desenvolvimento, com especial atenção, em primeiro lugar, às diversas formas de organização e de participação nos processos de tomada de decisões e à organização dos diversos grupos de interesses, formados em torno das necessidades percebidas como comuns. E, em segundo lugar, ao tipo e força das interações entre a sociedade civil e os governos locais e regionais, assim como outras instâncias instituídas pelo setor público.

Assim, as diferenças de gênero e idade, bem como a diversidade étnica, devem ser vistas como atributos ou recursos socioculturais que pedem formas específicas de tecido social para o bem comum. Portanto, os laços de interação social são de importância decisiva para promover e consolidar o processo de participação e democratização regional e local. Enfatiza-se a bagagem de conhecimento, informação, capacidade e destreza das populações específicas, qualidades pertinentes para gerar valor agregado em dados processos produtivos e para distribuir benefícios gerados por esses processos da melhor maneira possível.

Em torno do desenvolvimento rural, não se deve ater ao apontamento de vantagens ou obstáculos geográficos de localização e sim, de estudar a montagem das "redes", das "convenções", em suma, das instituições que permitem ações cooperativas - que incluem, evidentemente, a conquista de bens públicos como educação, saúde, informação - capazes de enriquecer o tecido social de certa localidade (NAZZARI, 2003).

Entre duas ou mais comunidades com a mesma quantidade de recursos instrucionais (capital humano) e materiais (capital físico), o que as distingue, no que tange ao desempenho de seus membros, é a existência de capital social, isto é, a existência de laços de confiança e reciprocidade estabelecidos, que tornarão possíveis a mobilização dos indivíduos para a ação coletiva (PASSADOR et al., 2005). Neste sentido, o conceito de capital social foi definido como:

\begin{abstract}
O conjunto de recursos atuais ou potenciais que estão ligados à posse de uma rede durável de relações mais ou menos institucionalizadas de interconhecimento e de inter-reconhecimento ou, em outros termos, a vinculação a um grupo, como um conjunto de agentes que, não somente são dotados de propriedades comuns, mas também são unidos por ligações permanentes e úteis. Essas relações são irredutíveis a relações objetivas de proximidade no espaço físico (geográfico) ou no espaço econômico e social, porque são fundadas em trocas inseparavelmente materiais e simbólicas cuja instauração e perpetuação supõem o reconhecimento dessa proximidade (BORDIEU, 1980 apud MATOS, 2002, p. 68).
\end{abstract}

De acordo com Peres (2003), mais importante que vantagens competitivas dadas por atributos naturais, de localização ou setoriais, é o fenômeno da proximidade social que 
DORNELAS, M. A.; SANTOS, A. A.; JORGE, M. L. Relações de confiança e satisfação com as condições sociais em uma microbacia em Minas Gerais

permite uma forma de coordenação entre os atores capazes de valorizar o conjunto do ambiente em que atuam e, portanto, de convertê-lo em base para empreendimentos inovadores. Corrobora ainda Nazzari (2006), quando menciona que o capital social é uma teia invisível que sustenta todas as relações sociais.

Portanto, se a sociedade não for organizada e seus níveis de confiança forem baixos, a desconfiança impede as pessoas de associarem-se, cooperarem e participarem nas questões políticas emergentes para o desenvolvimento das comunidades em que vivem. Sabe-se que as crenças e valores culturais, bem como a abertura para novos conhecimentos e técnicas vivenciadas e trocadas pelos demais produtores rurais, podem formar uma importante rede de cooperação e expandir o capital social e o desenvolvimento sustentável nas comunidades.

Para Sachs (2004) a produção de meios de subsistência depende da combinação de acesso a ativos requeridos para a produção de bens e serviços para autoconsumo, no âmbito da economia doméstica; acesso ao treinamento e assistência técnica, técnicas e ativos necessários e produção de bens orientados para o mercado mediante o autoemprego; disponibilidade de trabalho decente; acesso universal aos serviços públicos; acesso à habitação construída e disponibilidade de tempo livre para atividades não produtivas. $\mathrm{O}$ autor menciona que, para que ocorra um desenvolvimento que inclua os menos favorecidos, requerse, acima de tudo, a garantia do exercício dos direitos civis, cívicos e políticos, e que, além disso, o conjunto da população também deveria ter iguais oportunidades de acesso a serviços públicos, tais como educação, segurança, transporte, proteção à saúde e moradia.

A construção de uma sociedade sustentável envolve a promoção de uma educação que estimule a transformação ética e política dos indivíduos, bem como das instituições, promovendo mudanças que percorram o cotidiano individual e coletivo. De acordo com Sachs (2004), a educação é essencial para o desenvolvimento, pelo seu valor intrínseco, na medida em que contribui para o despertar cultural, conscientização e compreensão dos direitos humanos, aumentando a adaptabilidade e o sentido de autonomia, bem como a autoconfiança e estima. É claro que tem um valor instrumental com respeito à empregabilidade.

Os indicadores educacionais rurais do Brasil estão entre os piores da América Latina, como mostram os trabalhos da Comissão Econômica para a América Latina e Caribe (2002). Por isso, a juventude rural constitui um ator estratégico voltado para a formação de capital humano, que é necessário para impulsionar a formação de cadeias agroalimentares, aproveitar tecnologias de informática e, no geral, para elevar a competitividade da agricultura 
DORNELAS, M. A.; SANTOS, A. A.; JORGE, M. L. Relações de confiança e satisfação com as condições sociais em uma microbacia em Minas Gerais

(SEPÚLVEDA, 2005). Já, o acesso aos serviços de saúde faz parte de um objetivo mais amplo, que é o de melhorar a saúde das pessoas. Isto depende de uma alimentação adequada (segurança alimentar), do acesso a água limpa, da melhoria das condições de moradia e de trabalho, de uma melhor educação e de medidas preventivas, como vacinação.

Conforme Costabeber e Caporal (2003), a dimensão social representa precisamente um dos pilares básicos da sustentabilidade, uma vez que a preservação ambiental e a conservação dos recursos naturais somente adquirem significado e relevância quando o produto gerado nos agroecossistemas, em bases renováveis, também possa ser equitativamente apropriado e usufruído pelos diversos segmentos da sociedade. Sob o ponto de vista temporal, esta noção de equidade ainda se relaciona com a perspectiva intrageracional (disponibilidade de sustento mais seguro para a presente geração) e com a perspectiva intergeracional (não se pode comprometer hoje o sustento seguro das gerações futuras) (SIMÓN FERNÁNDEZ; DOMINGUEZ GARCIA, 2001).

A sustentabilidade social está vinculada ao padrão estável de crescimento, melhor distribuição de renda com redução das diferenças sociais, elevando a qualidade de vida do agricultor, de sua família e da comunidade local. Nesse sentido, é importante a participação dos governos municipal, estadual e federal em projetos sociais que possam contribuir com a permanência, de maneira digna, do agricultor em sua propriedade. Espera-se, finalmente, que em uma análise das situações sociais, possam se encontrar boas condições de educação, saúde, estradas, lazer, transporte coletivo, energia elétrica e/ou fontes alternativas de energia, assistência técnica, sistema de crédito, organização comunitária e sindicalização, condições sanitárias, aceitabilidade cultural e de aceitabilidade de novas tecnologias.

A dimensão social inclui, principalmente, a busca contínua de melhores níveis de qualidade de vida mediante a produção e o consumo de alimentos com qualidade biológica superior. Isso comporta, por exemplo, a eliminação do uso de insumos tóxicos no processo produtivo agrícola mediante novas combinações tecnológicas, ou ainda, por meio de opções sociais de natureza ética ou moral. Nesse caso, é a própria percepção de riscos e/ou efeitos maléficos da utilização de certas tecnologias sobre as condições sociais das famílias de agricultores que determina ou origina novas formas de relacionamento da sociedade com o meio ambiente. Trata-se de um modo de estabelecer uma conexão entre a dimensão social e a ecológica, sem prejuízo da dimensão econômica (um novo modo de "cuidar da casa" ou de "administrar os recursos da casa") (COSTABEBER; CAPORAL, 2003). Costabeber e 
DORNELAS, M. A.; SANTOS, A. A.; JORGE, M. L. Relações de confiança e satisfação com as condições sociais em uma microbacia em Minas Gerais

Caporal (2003) complementam ainda que, os saberes, os conhecimentos e os valores locais das populações rurais precisam ser analisados, compreendidos e utilizados como ponto de partida nos processos de desenvolvimento rural que, por sua vez, devem espelhar a "identidade cultural" das pessoas que vivem e trabalham em um dado agroecossistema.

\section{MATERIAL E MÉTODOS}

O método considerado adequado para a realização desta pesquisa foi o estudo de caso, pois neste tipo de abordagem, procura-se trabalhar com cenários sociais bastante específicos, tendo caráter de profundidade e detalhamento (ALENCAR, 1999; GIL, 1996; LAVILLE; DIONE, 1999; LEENDERS; ERSKINE, 1989; STAKE, 1994; VERGARA, 1998; YIN, 1989).

Optou-se, neste estudo de caso, pela pesquisa descritiva e exploratória. Segundo Gil (2009), a pesquisa descritiva tem como objetivo principal a descrição das características de determinadas populações ou fenômenos. Uma das características é a utilização de técnicas padronizadas de coleta de dados e a pesquisa exploratória visa proporcionar maior familiaridade com o problema, com vistas a torná-lo mais explícito.

A área de abrangência do estudo está inserida na Bacia do Rio São Francisco, envolvendo a região do Alto São Francisco (das nascentes à confluência do Rio Jequitaí, MG), especificamente na sub-bacia do Rio Ajudas. A microbacia dos Córregos São Pedro e Araras encontra-se completamente na área rural do município de Bambuí - MG, totalizando 7.415 ha.

Com o intuito de se alcançarem os objetivos propostos, a primeira etapa do estudo consistiu em identificar os produtores rurais inseridos na área de drenagem da microbacia dos Córregos São Pedro e Araras. Primeiramente, foi realizado um delineamento da área de drenagem, obtido por meio de SIG (Sistemas de Informações Georreferenciadas) e, em seguida, buscaram-se informações junto à Empresa de Assistência Técnica e Extensão Rural do Estado de Minas Gerais (EMATER) e ao Instituto Mineiro de Agropecuária (IMA) do município para identificar quem e quantos seriam estes produtores. Foram identificados 74 produtores rurais nesta microbacia. Deste total, obtiveram-se 94,59\% de respondentes, ou seja, 70 produtores, que são os sujeitos centrais desta pesquisa, sendo seis de grande porte, nove de médio porte e cinquenta e cinco produtores de pequeno porte. 
DORNELAS, M. A.; SANTOS, A. A.; JORGE, M. L. Relações de confiança e satisfação com as condições sociais em uma microbacia em Minas Gerais

Os procedimentos de coleta dos dados foram realizados por meio de dados primários e secundários. Os dados secundários foram obtidos por meio de pesquisa bibliográfica e permitiram a construção da fundamentação teórica e caracterização da área de estudo. $\mathrm{O}$ instrumento de coleta dos dados junto aos produtores rurais foi um questionário semiestruturado. Para a análise dos dados das entrevistas utilizou-se da análise de conteúdo proposta por Bardin (1979) e Minayo (2000).

\section{RESULTADOS E DISCUSSÃO}

Este tópico apresenta a caracterização geral dos produtores rurais respondentes (sexo, idade, escolaridade, tempo na atividade e porte familiar), as relações de confiança apresentadas pelos produtores sobre dezessete instituições e também a satisfação quanto ao acesso às condições sociais na microbacia estudada.

\subsection{Caracterização geral dos produtores rurais respondentes}

Este item aborda as características gerais dos produtores rurais respondentes, quais sejam: sexo, idade, escolaridade, tempo na atividade, composição familiar e o porte dos produtores.

\subsubsection{Sexo, idade, escolaridade, tempo na atividade e porte familiar}

A maioria dos entrevistados é do sexo masculino (89\%) e apenas $11 \%$ são mulheres. A divisão do trabalho nas unidades de produção familiar provoca uma masculinização não só da produção, mas de todo o meio rural. Esse é apenas um exemplo das várias condições sociais que fazem do meio rural um lugar menos propício para as mulheres, especialmente as mais jovens, tornando-o, cada vez mais, idoso e masculino (CAMARANO; ABRAMOVAY, 1999). Comprovando tal situação, a idade da maioria dos produtores rurais entrevistados encontra-se entre 56 a 65 anos (31,43\%), de 46 a 55 (24,29\%) e mais de 65 anos $(21,43 \%)$, enquanto que a idade abaixo de 45 anos representou uma porcentagem menor de respondentes: de 36 a 45 anos $(14,29 \%)$, de 26 a $35(7,14 \%)$ e menor ainda de produtores rurais com menos de 25 anos $(1,43 \%)$. 
DORNELAS, M. A.; SANTOS, A. A.; JORGE, M. L. Relações de confiança e satisfação com as condições sociais em uma microbacia em Minas Gerais

A idade foi uma variável importante, pois permitiu identificar se as famílias que participaram dessa pesquisa estão sofrendo o processo de envelhecimento - o que pôde assim ser confirmado -. Comparando com os aspectos demográficos nacionais, verifica-se que o processo de envelhecimento na comunidade em estudo não é um acontecimento isolado, pois Duncan et al. (2004), ressaltam que a distribuição etária revela expressivo envelhecimento da população brasileira, juntamente com outros indicadores que mostram a diminuição da taxa de fecundidade e o aumento da longevidade da população.

O Censo Agropecuário do Instituto Brasileiro de Geografia e Estatística (IBGE, 2006), revelou o baixo nível de escolaridade dos produtores agropecuários. No presente estudo foi revelado que a escolaridade da maioria dos respondentes foi o primário completo com $22,86 \%$, em segundo lugar o primário incompleto com 15,71\%. Além disso, 7,14\% dos respondentes não são alfabetizados ou somente assinam o nome. Os pesquisadores Ney e Hoffman (2009) concluíram em sua pesquisa que das pessoas com 25 anos ou mais de idade, vivendo no meio rural, "26,3\% têm escolaridade inferior a um ano e 46,7\% apenas o ensino primário", e completam: "quase $75 \%$ da população adulta, portanto, sequer tem o primeiro ano do antigo ensino ginasial". O efeito dessas diferenças reflete, de acordo com os números, diretamente no rendimento médio dos trabalhadores agrícolas e não agrícolas nas áreas oficialmente rurais. $\mathrm{Na}$ avaliação dos pesquisadores, a baixíssima escolaridade da população mais pobre restringe sua capacidade de defender seus direitos e de participar de forma mais ativa na vida social e política do país, o que poderia gerar mudanças institucionais importantes a favor da equidade. Lanjouw (1999) e Reardon (2001) também destacam que o baixo nível de escolaridade da população restringe o crescimento das atividades não agrícolas, principalmente das mais produtivas e dinâmicas.

Todavia, $12,86 \%$ dos produtores têm formação de técnico agrícola, o que pode facilitar suas atividades rurais e 11,43\% têm curso superior completo, com as formações profissionais em agronomia, direito, administração, processamento de dados, física e engenharia civil. Finalmente, três produtores eram pós-graduados $(4,29 \%)$ nas áreas de extensão rural, educação e meteorologia. O nível de escolaridade e a experiência com outras atividades profissionais são ingredientes importantes para desencadear o processo de transformação. Certamente não são condições indispensáveis, pois agricultores com baixa escolaridade, e vivência apenas com a agricultura, conseguem certificação e se colocam positivamente no mercado. Entretanto, produtores com capacitação formal e conhecimento de 
DORNELAS, M. A.; SANTOS, A. A.; JORGE, M. L. Relações de confiança e satisfação com as condições sociais em uma microbacia em Minas Gerais

mercado desempenham o papel de trazer novas visões e quebrar antigos paradigmas, promovendo um efeito de multiplicação das práticas orgânicas (MAZZOLENI; NOGUEIRA, 2006).

Para Lacki (2000), o conhecimento é emancipador de dependências do produtor rural. Ao dotá-lo de mais autoconfiança e autossuficiência técnica, permite que ele possa ser mais eficiente, buscando soluções para seus próprios problemas.

Também se demonstrou elevada a experiência nas atividades agropecuárias, tendo em vista que a porcentagem de respondentes com idade superior aos 45 anos também é alta. A grande maioria dos respondentes, 56\%, está lidando com a atividade agrária há mais de 30 anos e em muitos casos a vida toda. Quatorze por cento exercem a atividade de 21 a 30 anos e 19\% de 11 a 20 anos. Apenas 7\% dos produtores estão na atividade de 6 a 10 anos e $4 \%$ há menos de 5 anos.

Em muitas atividades profissionais, a experiência é valorizada como fator de sucesso. No meio rural, embora nem sempre essa experiência se traduza em termos financeiros, sua importância se reflete na adoção de novas práticas agrícolas e na redução dos riscos inerentes à atividade.

A transmissão dos direitos sobre a propriedade de uma geração à outra pôde ser identificada, tendo em vista que, grande parte dos produtores entrevistados mencionou que permaneceram no campo para dar continuidade ao trabalho de seus pais. Nota-se, ainda, pouco ou baixo desenvolvimento do empreendedorismo rural por parte de indivíduos oriundos da cidade, ou de uma migração da cidade para o campo, e dados do IBGE comprovam que essa migração é inversa, ou seja, do meio rural para as cidades. Os dados evidenciam que a maioria dos respondentes conhece a comunidade há um tempo considerável, alguns inclusive nasceram ali, possuindo boas condições para fornecer informações consistentes sobre a microbacia.

O total de brasileiros trabalhando no campo caiu $30 \%$, de 23,3 para 16,4 milhões desde 1985, conforme o IBGE. Nesse período, o número de pessoas por propriedade passou de 4 para 3. O campo dispensou 6,9 milhões de pessoas. O produtor que permanece no meio rural tem cerca de 45 anos e depende da esposa, de um dos filhos ou de um empregado para produzir (IBGE, 2006).

No estudo, verificou-se que a composição da maioria das famílias dos respondentes é formada por 4 a 5 pessoas (63\%), 17\% das famílias estão entre 6 a 9 membros e $13 \%$ têm 2 a 
DORNELAS, M. A.; SANTOS, A. A.; JORGE, M. L. Relações de confiança e satisfação com as condições sociais em uma microbacia em Minas Gerais

3 indivíduos. Famílias compostas por muitos membros, acima de 10 pessoas, representaram uma minoria de 7\%. A predominância de famílias compostas por 4 ou 5 indivíduos ratifica uma tendência de estruturas familiares mais reduzidas.

\subsection{Relações de confiança}

Muitos estudos abordaram a importância das relações de confiança no contexto rural para mensurar o capital social. Relações familiares e de vizinhança, relações de amizade e relações profissionais podem constituir formas latentes de capital social e esse conjunto de normas informais é que promove a cooperação entre dois ou mais indivíduos. Logo, é da existência e do compartilhamento dessas normas que surge confiança e redes entre indivíduos (ABRAMOVAY, 2000; BOURDIEU, 1980; CASTILHOS, 2002; VILLELA, 2001).

Granovetter (1973, 1985 apud LAZZARINI; CHADDAD; NEVES, 2000) faz uma qualificação da natureza de laços sociais inseridos em redes de relacionamentos interpessoais: um laço forte entre dois indivíduos envolve uma elevada dose de tempo e esforço dedicado à relação, feição emocional, confiança e reciprocidade. Logo, é um relacionamento que se molda e autorreforça ao longo do tempo. Um laço fraco é exatamente o oposto dessa situação, envolvendo transações pontuais entre agentes, em que a identidade dos indivíduos tem menor importância e questões de confiança e reciprocidade são mínimas.

A confiança do produtor rural, em dezessete instituições de apoio, foi levantada. As instituições que inspiraram maior confiança, demonstrando laços mais fortes com produtores, foram, na ordem de importância, a família (90\%), os vizinhos (77,14\%), EMATER (58,57\%), universidades (57,14\%), igreja (56,52\%), Instituto Brasileiro de Meio Ambiente e dos Recursos Naturais Renováveis (IBAMA) $(38,57)$, Instituto Estadual de Florestas (IEF) $(32,56 \%)$ e ministério público $(31,43 \%)$.

As instituições de apoio com maior destaque, em que os produtores confiam parcialmente, foram as empresas $(65,22 \%)$, governo federal $(51,43 \%)$, governo estadual (48,57\%), mídia (48,57\%), IEF (32, 86\%), sindicato e associações (37,14\%), sistema judiciário $(34,29 \%)$ e polícia ambiental $(34,29 \%)$.

As instituições que mais geraram desconfiança, ou que denotaram laços sociais mais fracos com os produtores rurais, foram o governo municipal com $47,14 \%$, o sistema judiciário $(27,14 \%)$, os sindicatos e associações $(25,71 \%)$ e o ministério público $(24,29 \%)$. 
DORNELAS, M. A.; SANTOS, A. A.; JORGE, M. L. Relações de confiança e satisfação com as condições sociais em uma microbacia em Minas Gerais

É importante ressaltar que as instituições menos conhecidas dos produtores, ou cujas relações de confiança não puderam ser avaliadas, foram as ONGs (Organizações NãoGovernamentais) com 55,71\%, sindicatos e associações (25,71\%), ministério público e IEF, ambos com 20\% das opiniões dos respondentes (Figura 1).

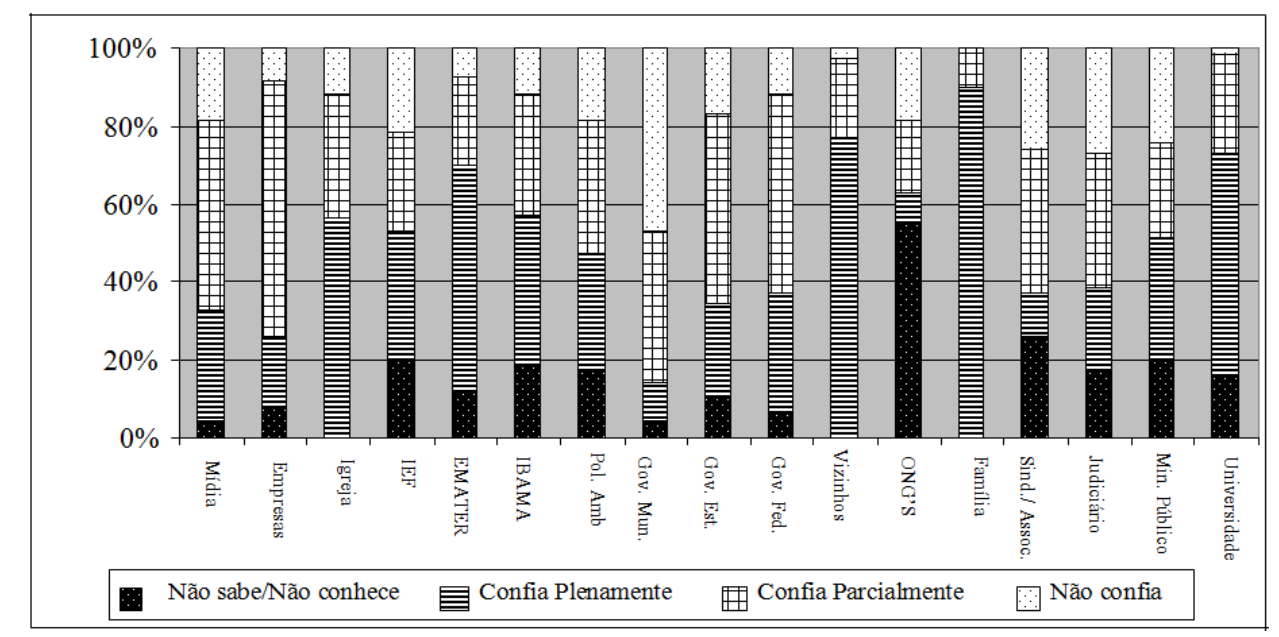

Figura 1 Confiança em algumas instituições de apoio aos produtores Fonte: Dados da pesquisa (2011).

As instituições de maior confiança para pequeno, médio e grande produtor foram famílias e vizinhos, em primeiro e segundo lugar, respectivamente. Em terceiro lugar, a instituição de maior confiança para os grandes foi a universidade, para os médios a EMATER e a igreja para os pequenos. Na quarta posição e empatados o IEF e EMATER foram de total confiança para os grandes, bem como mídia e universidade para os médios e EMATER para os pequenos.

Do lado oposto de avaliação, tem-se que os pequenos produtores confiam menos no governo municipal (49\%), sindicatos rurais e associações (25\%), polícia ambiental, ministério público e sistema judiciário com $20 \%$ dos produtores afirmando não confiar. Os médios produtores confiam menos no IEF e sistema judiciário, ambos com 55,56\% das opiniões dos entrevistados, seguido pelo governo municipal e Organizações não Governamentais (ONGs) com $44 \%$ e com $33 \%$ o governo estadual e ministério público. Por fim, as instituições que os grandes produtores mais desconfiam, dentre as 17 apresentadas, foram o sistema judiciário e ministério público, ambos com 50\% das opiniões, empatadas, também, estão o governo municipal, os sindicatos e associações e a igreja com 33\% de desconfiança.

Monastério (2000) distinguiu três tipos de capital social: capital social institucional (descreve as relações sociais existentes entre a sociedade civil e o Estado), capital social 
DORNELAS, M. A.; SANTOS, A. A.; JORGE, M. L. Relações de confiança e satisfação com as condições sociais em uma microbacia em Minas Gerais

extracomunitário (descreve as relações sociais geradoras de capital que determinada comunidade; estabelece com grupos sociais e econômicos externos) e capital social comunitário (refere-se às relações sociais comunitárias dos indivíduos). Atrelando as relações sociais a relações de confiança compreendidas pelos produtores entrevistados, ficou evidente a presença do capital social comunitário, pois os respondentes demonstraram um alto grau de confiança em sua família e vizinhança rural.

O capital social extracomunitário e institucional para as instituições analisadas oscilaram bastante com relação aos níveis de confiança em cada instituição e por isso entendeu-se que estão presentes, porém não de maneira tão marcante como o capital social comunitário. Isso indica que as relações sociais presentes entre os vizinhos podem gerar formas combinadas de associação entre os mesmos. Além do mais, o capital social institucional e extracomunitário merecem ser reforçados e para isso é necessário que as instituições, tanto públicas quanto as privadas, promovam ações mais participativas junto à comunidade de produtores rurais.

Desta forma, é notória a importância dos laços familiares e do sentimento de vizinhança estabelecido entre a maioria dos pesquisados, que se configura como uma das premissas básicas para reconhecimento de capital social inerente à comunidade pesquisada. É interessante observar que duas instituições de caráter técnico e público como a EMATER e as universidades obtiveram uma credibilidade maior do que a igreja. Em relação às instituições de menor prestígio, o governo municipal configurou-se com um alto índice de desconfiança. Além disso, é importante salientar o quanto as ONGs são desconhecidas no meio rural estudado.

\subsection{Satisfação quanto ao acesso às condições sociais na microbacia estudada}

Os produtores rurais foram indagados sobre suas opiniões gerais e específicas referentes às condições sociais a que têm acesso e as respostas obtidas indicam que $40 \%$ sentem-se mais ou menos satisfeitos. Trinta e nove por cento (39\%) sentem-se satisfeitos e $21 \%$ não se sentem satisfeitos com as condições sociais.

Dentre os entrevistados, que representaram aqueles quarenta por cento (40\%) que se sentiram mais ou menos satisfeitos, a maioria $(68,5 \%)$ relatou que a situação das estradas os incomoda e atrapalha mais, por gerar prejuízos diretos no deslocamento do produtor, crianças para a escola e escoamento da produção. Em segundo lugar destacaram-se problemas 
DORNELAS, M. A.; SANTOS, A. A.; JORGE, M. L. Relações de confiança e satisfação com as condições sociais em uma microbacia em Minas Gerais

referentes à educação de seus filhos com 12,2\%, demonstrando apreensão sobre o transporte escolar e sobre as perspectivas de melhoria da escolaridade. Em terceiro lugar, apareceram transtornos relativos à saúde $(9,7 \%)$. Na quarta posição, com 7,2\%, foi apontada a dificuldade de acesso aos meios de comunicação, principalmente relativos aos sinais de recepção de telefonia móvel e internet, ou seja, inseridos no contexto da exclusão digital. A seguir surgiram, com 2,4\%, as problemáticas referentes a necessidades de melhorias em sua moradia.

Alguns trechos de entrevistas que representam os discursos sobre as condições sociais são elencados a seguir: "Estou satisfeito em partes, porque faço o que gosto, porém deixo de fazer outras coisas que também gosto. Estou satisfeito com a minha habitação, saúde, educação, porém insatisfeito com a condição da estrada" (RELATO DE ENTREVISTA PRODUTOR 43).

Outro discurso elucida de maneira objetiva a percepção do mesmo respondente sobre as condições de educação e estrada: "Estou mais ou menos satisfeito porque, por exemplo, quando chove a estrada fica péssima e aí o ônibus escolar não tem como vir buscar as crianças e também gera contrariedade das pessoas para vir trabalhar" (RELATO DE ENTREVISTA - PRODUTOR 20). A fala de outro denota a insatisfação com as condições de saúde: "a habitação é boa, mas o resto não muito, por exemplo, por aqui não tem assistência médica" (RELATO DE ENTREVISTA - PRODUTOR 66).

Para os $21 \%$ de produtores rurais (15 respondentes) totalmente insatisfeitos, as causas de descontentamento giraram em torno da situação das estradas e da saúde (6 produtores). A educação dos filhos foi mencionada por 3 produtores como um motivo de preocupação, porque depois da oitava série o filho terá de ir para cidade continuar os estudos; existe na região a Escola Municipal do Pau Ferro, porém atende somente até o ensino fundamental.

Destacam-se aqui os relatos de dois produtores: "Não estou satisfeito porque a estrada é sem manutenção, saúde não tem acesso e escola tem de ir pra cidade" (RELATO DE ENTREVISTA - PRODUTOR 04); “Não sinto não, porque, por exemplo, não vejo assistência médica na zona rural. Quanto à estrada, se chover fica intransitável. Segurança não tem, isso temos sorte porque não tem o ladrão, mas não tem policiamento e quanto à educação até tá razoável, mas ainda tem o que melhorar" (RELATO DE ENTREVISTA PRODUTOR 58). Os outros 6 produtores apontaram problemas gerais, seus discursos posicionam-se no sentido de que não há acesso aos serviços sociais na microbacia e que têm 
DORNELAS, M. A.; SANTOS, A. A.; JORGE, M. L. Relações de confiança e satisfação com as condições sociais em uma microbacia em Minas Gerais

de recorrer ao município em busca de solução para os problemas de ordem social. O relato do produtor 18 demonstra essa opinião: "não tem nada lá que se necessita e que atenda as nossas necessidades sociais".

A tranquilidade do local onde vivem, a melhoria da condição de vida no campo se comparada a décadas passadas, o fato de gostarem das atividades que desenvolvem, o acesso à escola municipal rural para seus filhos (com transporte escolar diário) e a fé em Deus representam motivos de satisfação para os $39 \%$ de produtores rurais que se sentiram satisfeitos com as condições sociais.

Trechos de relatos dos entrevistados demonstram essa situação. "Tô muito satisfeita. Escola boa, estrada boa, somos privilegiados aqui." (RELATO DE ENTREVISTA PRODUTOR 59); "Tô porque a educação melhorou muito e o resto eu to satisfeito" (RELATO DE ENTREVISTA - PRODUTOR 63); “Tá ótimo porque ta dando para viver, trazer as contas pagas e ainda sobra um pouquinho." (RELATO DE ENTREVISTA PRODUTOR 21); "Sinto satisfeita porque é o que eu gosto" (RELATO DE ENTREVISTA PRODUTOR 23); “Estou sim, graças à Deus temos saúde e não precisamos de tanta coisa assim pra viver" (RELATO DE ENTREVISTA - PRODUTOR 43); "Porque se a gente tiver fé em Deus e 'tando' trabalhando, tem de ficar satisfeito" (RELATO DE ENTREVISTA PRODUTOR 01).

A satisfação com as condições sociais relativas ao porte demonstra que os pequenos e médios estão mais satisfeitos. Dos pequenos, 24 (43,64\%) estão totalmente satisfeitos, 22 (40\%) mais ou menos e 9 (16,36\%) insatisfeitos. Dos médios, 4 (44,44\%) estão totalmente satisfeitos, $2(22,22 \%)$ mais ou menos e $3(33,33 \%)$ insatisfeitos. A maioria dos grandes encontra-se insatisfeita sendo $3(50 \%)$ insatisfeitos, 1 satisfeito $(16,67 \%)$ e $2(33,33 \%)$ totalmente satisfeitos.

\section{CONCLUSÕES}

Pode-se concluir que as instituições que inspiraram maior confiança, demonstrando laços mais fortes com os produtores foram, na ordem de importância, a família, os vizinhos, EMATER, universidades, igreja, IBAMA, IEF e ministério público.

A percepção dos produtores rurais quanto às condições sociais permitiu identificar a convergência de pequenos, médios e grandes produtores relativa à avaliação negativa das 
DORNELAS, M. A.; SANTOS, A. A.; JORGE, M. L. Relações de confiança e satisfação com as condições sociais em uma microbacia em Minas Gerais

condições das estradas e, positivamente, no que tange à segurança e capital social comunitário forte. A forma como foi percebido o acesso às condições sociais pelos produtores rurais pode ter origem na escolaridade e, consequentemente, no porte dos produtores. Neste trabalho, observou-se que a escolaridade está intimamente relacionada ao porte. Assim, a maioria dos produtores com ensino superior é de grande porte; os de médio porte, em sua maioria, têm o ensino médio ou técnico, enquanto a concentração de baixa escolaridade, com ensino fundamental e primário, ficou entre os pequenos produtores.

Percebeu-se neste trabalho que os produtores de pequeno porte estão, de forma geral, mais satisfeitos com as condições sociais, ao passo que os de médio e grande porte demonstraram maior insatisfação. Assim, a maior escolaridade representou maior acesso à informação e, consequentemente, maior grau de urgência sobre o acesso às condições sociais.

Finalmente, conhecer, diagnosticar, retratar e documentar a realidade holística e de mesorregião (bacias hidrográficas) torna-se um meio (canal) para que estratégias sustentáveis de melhorias das condições atuais possam ser alcançadas com sucesso.

\section{REFERÊNCIAS}

ABRAMOVAY, R. O capital social dos territórios: repensando o desenvolvimento rural. Revista de Economia Aplicada, São Paulo, v. 4, n. 2, p. 379-397, abr./jun. 2000. ABRAMOVAY, R. Para una teoría de los estudios territoriales. 2006. Disponível em: <http://www.econ.fea.usp.br/ abramovay/artigos_cientificos.htm>. Acesso em: 24 fev. 2017.

ALENCAR, E. Introdução à metodologia de pesquisa social. Lavras: UFLA, 1999.

BARDIN, L. Análise de conteúdo. Lisboa: Edições 70, 1979.

BOURDIEU, P. Le capital social: notes provisoires. Actes de la Recherche en Sciences

Sociales, Paris, v. 31, n. 1, p. 2-3, 1980. Disponível em: <http://www. persee.fr/articleAsPDF/arss_03355322_ 1980_num_31_1_2069/article_arss_0335-5322_1980_num_31_1_2069.pdf >. Acesso em: 4 jun. 2011.

BOWERS, J.; HOPKINSON, P. The treatment of landscape in project appraisal: consumption and sustainability approaches. Project Appraisal, Surrey, v. 9, n. 2, p. 110-118, 1994.

BRASIL. Constituição (1988). Constituição da República Federativa do Brasil, 1988. São Paulo: Ática, 1988. 
INSTITUTO BRASILEIRO DE GEOGRAFIA E ESTATÍSTICA - IBGE. Censo Agropecuário. Brasília, 2006.

CAMARANO, A. A.; ABRAMOVAY, R. Êxodo rural, envelhecimento e masculinização no Brasil: panorama dos últimos 50 anos. Rio de Janeiro: IPEA, 1999.

CASTILHOS, D. S. B. Capital social e políticas públicas: um estudo da linha infraestrutura e serviços aos municípios do PRONAF. 2002.172 p. Dissertação (Mestrado em Desenvolvimento Rural) - Universidade Federal do Rio Grande do Sul, Porto Alegre, 2002.

COMISSÃO ECONÔMICA PARA A AMÉRICA LATINA E O CARIBE. Indicadores rurais na América Latina. 2002. Disponível: 〈www.cepal.org.br>. Acesso em: 30 jan. 2010.

CONFERÊNCIA DAS NAÇÕES UNIDAS PARA O MEIO AMBIENTE E O

DESENVOLVIMENTO. Agenda 21. Rio de Janeiro: MMA, 1992.

COSTABEBER, J. A.; CAPORAL, F. R. Possibilidades e alternativas do desenvolvimento rural sustentável. In: VELA, H. (Org.). Agricultura familiar e desenvolvimento rural sustentável no Mercosul. Santa Maria: UFSM, Pallotti, 2003. p. 157-194.

DUNCAN, B. B. et al. Medicina ambulatorial: condutas de atenção primária baseadas em evidências. 3. ed. Porto Alegre: Artmed, 2004.

FÓRUM OESTE DE ENTIDADES PARA O DESENVOLVIMENTO SUSTENTÁ VEL DA AGRICULTURA FAMILIAR. Sustentabilidade e seus vários significados. Jornal Roça Viva, Cascavel, v. 1, n. 1, fev. 2003. Disponível em: <www.agriculturafamiliar.org.br>. Acesso em: jun. 2010.

GIL, A. C. Como elaborar projetos de pesquisa. 3. ed. São Paulo: Atlas, 1996.

GIL, A. C. Como elaborar projetos de pesquisa. 4. ed. São Paulo: Atlas, 2009.

LACKI, P. Rentabilidade na agricultura: com mais subsídios ou com mais profissionalismo? In: CONGRESSO BRASILEIRO DAS RAÇAS ZEBUÍNAS, 4., Uberaba, 2000. Anais... Uberaba: ABCZ, 2000. p. 167-183.

LANJOUW, P. The rural non-farm sector: a note on policy options. In: WORLD BANK WORKSHOP ON NON-FARM RURAL SECTOR AND POVERTY ALLEVIATION. 1999. Mimeo.

LAVILlE, C.; DIONE, J. A construção do saber. Belo Horizonte: UFMG, 1999. 
LAZZARINI, S. G.; CHADDAD, F. R.; NEVES, M. F. O conceito de capital social e aplicações para desenvolvimento e estratégia sustentável. Preços Agrícolas, Piracicaba, p. 10-14, maio 2000.

LEENDERS, M. R.; ERSKINE, J. A. Case research: the case writing process. Ontario: University of Western Ontario, 1989.

LEWANDOWSKI, I.; HARDTLEIN, M.; KALTSCHMITT, M. Sustainable crop production: definition and methodological approach for assessing and implementing sustainability. Crop Sciences, Madison, v. 39, p. 184-193, 1999.

MATOS, D. L. et al. Projeto Bambuí: avaliação de serviços odontológicos privados, públicos e de sindicato. Revista de Saúde Pública, São Paulo, v. 36, n. 2, p. 237-243, 2002.

MAZZOLENI, E. M.; NOGUEIRA, J. M. Agricultura orgânica: características básicas do seu produtor. Revista de Economia e Sociologia Rural, Brasília, DF, v. 44, n. 2, p. 263-293, 2006.

MINAYO, M. C. S. O desafio do conhecimento: pesquisa qualitativa em saúde. 7. ed. São Paulo: Hucitec; Rio de Janeiro: Abrasco, 2000.

MONASTÉRIO, L. M. Putnam no Pampa: capital social e a metade Sul do Rio Grande do Sul. Pelotas: UFPEL, 2000.

NAZZARI, R. K. Capital social, cultura e socialização política: a juventude brasileira. Tese (Doutorado em Ciência Política) - Universidade Federal do Rio Grande do Sul, Porto Alegre, 2003.

NAZZARI, R. K. Juventude brasileira: capital social, cultura e socialização política. Cascavel: Edunioste, 2006.

NEHER, D. Ecological sustainability in agricultural systems: definition and measurement. Journal of Sustainable Agriculture, Binghamton, v. 2, n. 3, p. 51-61, 1992.

NEY, M. G.; HOFFMANN, R. Educação, concentração fundiária e desigualdade de rendimentos no meio rural brasileiro. Revista de Economia e Sociologia Rural, Brasília, DF, v. 47, n. 1, p. 147-181, 2009.

OLIVEIRA, J. H. R. MAIS: método para avaliação de indicadores de sustentabilidade organizacional. 2002. 196 f. Tese (Doutorado em Engenharia de Produção) - Universidade Federal de Santa Catarina, Florianópolis, 2002. 
DORNELAS, M. A.; SANTOS, A. A.; JORGE, M. L. Relações de confiança e satisfação com as condições sociais em uma microbacia em Minas Gerais

PASSADOR, J. L. et al. Capital social e desenvolvimento rural sustentável: uma abordagem sistêmica da verticalização da agricultura familiar. In: SIMPÓSIO DE ENGENHARIA DA PRODUÇÃO, 12., 2005, Bauru. Anais... Bauru: [s. n.], 2005. 1 CD ROM.

PERES, F. C. Capital social: a nova estrela do crescimento econômico. 2003. Disponível em: <www.pa.esalq. usp.br>. Acesso em: 6 ago. 2009.

REARDON, T. Rural nonfarm employment and incomes in Latin America: overview and policy implications. World Development, Oxford, v. 29, n. 3, mar. 2001.

SACHS, I. Desarrollo sustentable, bio-industrialización descentralizada y nuevas configuraciones rural urbanas. Los casos de India y Brasil. Pensamiento Iberoamericano, Madrid, v. 46, p. 235-256, 1990.

SACHS, I. Desenvolvimento: includente, sustentável, sustentado. Rio de Janeiro: Garamond, 2004.

SEPÚLVEDA, S. Desenvolvimento microrregional sustentável: métodos para planejamento local. Tradução de Dalton Guimarães. Brasília, DF: IICA, 2005.

SIMÓN FERNÁNDEZ, X.; DOMINGUEZ GARCIA, D. Desenvolvimento rural sustentável: uma perspectiva agroecológica. Agroecologia e Desenvolvimento Rural Sustentável, Porto Alegre, v. 2, n. 2, p. 17-26, abr./jun. 2001.

STAKE, R. E. Case studies. In: DEZIN, N. K.; LINCOLN, Y. S. Handbook of qualitative researchs. London: Sage, 1994. p. 236-242.

VACCARI, A. V. O rural revisto como sustentabilidade, estudo de caso em Gramado e Canela, Rio Grande do Sul, Brasil. 2006. Disponível em: <http:// www.alasru.org/cdalasru2006/29\%20GT\%20Andr\%C3\%A9\%20Volkart\%20 Vaccari.pdf>. Acesso em: 22 jun. 2010.

VERGARA, S. C. Projetos e relatórios de pesquisas em administração. São Paulo: Atlas, 1998.

VILLELA, G. A. P. O processo de construção de capital social e a influência da extensão rural: estudo de caso do Projeto Área-Piloto do RS, envolvendo quatro municípios do Planalto Sul-Riograndense. 2001. 64 p. Monografia (Especialização em Desenvolvimento Rural) - Universidade Federal do Rio Grande do Sul, Porto Alegre, 2001.

YIN, R. K. Case study research: design and methods. Bervely Hills: Sage, 1989. 


\title{
RELATIONSHIPS OF TRUST AND SATISFACTION WITH SOCIAL CONDITIONS IN A WATERSHED IN MINAS GERAIS
}

\begin{abstract}
The purpose of this work is to present the perception about the relationships of trust in relation to supporting bodies for farmers and satisfaction with social conditions of farmers (small, medium and large) on the watershed of São Pedro and Araras streams in the city of Bambuí - MG. Therefore a qualitative survey was conducted based on a descriptive study. The data collection was made through a semi structured questionnaire to 70 agriculturists located in the watershed. It was obtained that the institutions that inspired greater confidence and showed stronger ties with the farmers were, in order of importance, family, neighbors, EMATER, universities, church, IBAMA, IEF and the public prosecution. Regarding satisfaction with the social conditions, the main limiting factors were mainly related to road conditions and lack of support for small producers (technical assistance, information on public policies). It can be concluded that in the studied watershed there are nice relationships of trust between families and neighbors, demonstrating a strong community social capital.
\end{abstract}

Keywords: Watershed. Social capital. Relationships of trust. Satisfaction.

Recebido em: 24/06/2016

Aprovado em: 15/07/2016

Publicado em: 06/10/2017 